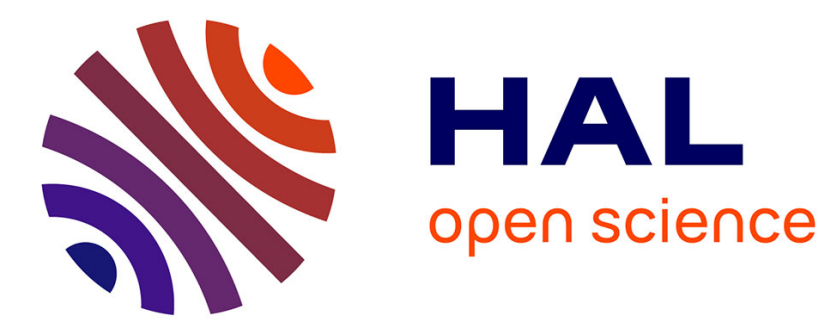

\title{
The European carbon market (2005-2007): banking, pricing and risk-hedging strategies
}

\author{
Julien Chevallier
}

\section{To cite this version:}

Julien Chevallier. The European carbon market (2005-2007): banking, pricing and risk-hedging strategies. 2010. halshs-00458787

\section{HAL Id: halshs-00458787 \\ https://shs.hal.science/halshs-00458787}

Preprint submitted on 22 Feb 2010

HAL is a multi-disciplinary open access archive for the deposit and dissemination of scientific research documents, whether they are published or not. The documents may come from teaching and research institutions in France or abroad, or from public or private research centers.
L'archive ouverte pluridisciplinaire HAL, est destinée au dépôt et à la diffusion de documents scientifiques de niveau recherche, publiés ou non, émanant des établissements d'enseignement et de recherche français ou étrangers, des laboratoires publics ou privés. 


\title{
The European carbon market (2005-2007): banking, pricing and risk-hedging strategies
}

\author{
Julien Chevallier* \\ Université Paris Dauphine
}

\begin{abstract}
At the stage of international post-Kyoto negotiations, the adoption of ambitious public policies raises an increasing interest, as society has a whole is more concerned by the scale of damages and the potential irreversibility linked to climate change. The introduction of a tradable permits market in Europe on January 1, 2005, in order to provide incentives to Member-States to take early abatement measures, may be seen as a decisive first step towards that direction. The creation of the EU ETS has indeed revealed the key role played by the European Union in the preservation of the global public good that constitutes the climate. This article reviews the market rules of the European carbon market during 2005-2007. More particularly, it synthesizes theoretical and empirical analyses of banking and borrowing provisions, price drivers and riskhedging strategies attached to tradable quotas, which were introduced to cover the $\mathrm{CO}_{2}$ emissions of around 10,600 installations in Europe.
\end{abstract}

Keywords: Climate Change Policy; Emissions Trading; EU ETS; European carbon market; Banking Borrowing; Carbon Pricing; Spot Prices; Futures Prices; Option Prices; Risk-Hedging Strategies.

\footnotetext{
* Julien Chevallier is Member of the Centre de Géopolitique de l'Energie et des Matières Premières (CGEMP) and the Laboratoire d'Economie de Dauphine (LEDa). He is also Visiting Researcher with EconomiX-CNRS and the Grantham Institute for Climate Change at Imperial College London. Address for correspondence: Place du Maréchal de Lattre de Tassigny, 75775 Paris Cedex 16, France. Email : julien.chevallier@ dauphine.fr

Acknowledgements: The author is thankful to Emilie Alberola, Benoit Cheze and Florian Ielpo for fruitful collaboration. I wish to thank also Simon Buckle, Derek Bunn, Thierry Brechet, Denny Ellerman, Pierre-Andre Jouvet, Valerie Mignon, Christian de Perthuis, and Gilles Rotillon for discussions on this topic. Helpful comments were received from seminar audiences at Imperial College, LSE, MIT-CEEPR, Oxford, Toulouse; and conferences at CORE, EAERE, EEA-ESEM, Envecon, IAEE. Finally, I wish to acknowledge financial support from the French Ministry of Research and Superior Education. The usual disclaimer applies.
} 


\section{Introduction}

The European Union Emissions Trading Scheme (EU ETS) has been created on January 1, 2005 to reduce by $8 \% \mathrm{CO}_{2}$ emissions in the European Union by 2012 , relative to 1990 emissions levels. This aggregated emissions reduction target in the EU has been achieved following differentiated agreements, sharing efforts between Member States based on their potential of decarbonization of their economy. The introduction of a tradable permits market has been decided to help Member States in achieving their targets in the Kyoto Protocol, entered into force on February 2005 following the ratification of Iceland, and which aims at reducing the emissions of six greenhouse gases (GHG) considered as the main cause of climate change. Among the Members of Annex B, these agreements include $\mathrm{CO} 2$ emissions reductions for 38 industrialized countries, with a global reduction of $\mathrm{CO}_{2}$ emissions by $5.2 \%$ (see Table 2). These agreements have been fostered by the United Nations Framework Convention on Climate Change (UNFCCC (2000)) which recognizes three principles: the precautionary principle ${ }^{1}$, the principle of common but differentiated responsibilities ${ }^{2}$, and the principle of the right to development ${ }^{3} .174$ countries, Australia being the latest on December 3, 2007, have ratified the Protocol, with the notorious exception of the United States. The first commitment period of the Kyoto Protocol goes from January 1, 2008 to December 31, 2012.

This political will has been reaffirmed at the international level during the UN Conference that took place in Bali on December 2007, where a roadmap of negotiations that should lead to a post-Kyoto agreement has been adopted. The United States are expected to cooperate, given the initiatives of emissions reduction introduced at the regional level ${ }^{4}$. The next round of negotiations will take place in Copenhagen on December 2009. As the Clean Development Mechanism $(\mathrm{CDM})^{5}$ has revealed the strong potential of $\mathrm{CO}_{2}$ emissions abatement in countries such as Brazil, China or India, the main issue of these negotiations is linked to achieving the largest possible level of cooperation, in order to avoid the well-known free riders behaviours, and to preserve the global public good that constitutes the climate. On this matter,

\footnotetext{
${ }^{1}$ Scientific uncertainty concerning the precise impacts of climate change does not justify delaying immediate action.

${ }^{2}$ Each signatory country recognizes the impact of its GHG emissions on climate change. The most industrialized countries carry a heavier historical responsibility, given their prior GHG intensive development, which translates into tighter targets.

${ }^{3}$ Action will be taken in accordance with the economic development of each country.

${ }^{4}$ We may cite the Regional Greenhouse Gas Initiative (RGGI), which contains several GHG reduction objectives in nine North-Eastern States, and the Assembly Bill 32 in California which aims at reducing $\mathrm{CO}_{2}$ emissions by $25 \%$ by 2020 relative to 1990 emissions levels, and by $80 \%$ by 2050 . At the federal level, the Climate Stewardship Act introduced by the Senator Lieberman- McCain did not find sufficient political support to become legally binding.

5 According to the article 12 of the Kyoto Protocol, CDM projects consist in achieving GHG emissions reduction in non-Annex B countries. After validation, the UNFCCC delivers credits that may be used by Annex B countries for use towards their compliance position.
} 
the European Union has clearly adopted a leadership position, which contrasts with its early reluctance during the first steps of the negotiation of the Kyoto Protocol.

On January 2008, the European Commission has extended the scope of its action against global warming by 2020 with the "energy and climate change" package. This package aims at reducing GHG emissions by $20 \%$, at increasing the use of renewable energy in energy consumption to $20 \%$, and at saving $20 \%$ of energy by increasing energy efficiency. The European carbon market, which has currently entered its Phase II (2008-2012), has been confirmed until 2020 also. Its scope has been extended to major sectors in terms of $\mathrm{CO}_{2}$ emissions growth, such as aviation and petro-chemical industries during 2013-2020. These repeated public policies in favour of climate protection aim at correcting the negative externality attached to the release of uncontrolled GHG emissions in the atmosphere and thus, according to the well-known principle in economics, at internalizing the social cost of carbon. At the same time, these initiatives reveal the difficulty to create a scarcity condition regarding $\mathrm{CO}_{2}$ emissions. These emissions indeed were not limited in the pre-existing institutional environment, and thus could not be considered as a scarce resource.

The European Union being at the forefront of environmental regulation dedicated to climate policies, this article reviews the market rules of the European carbon market during Phase I. It investigates the role played by the regulator, among the various choices at stake when creating a tradable permits market, on the behaviour of firms. Thus, this article contributes to the literature on the "birth" of the European carbon market (Convery et al. (2008), Convery (2009), Ellerman and Buchner (2008)), by focusing our attention on the study of several key provisions in a moving institutional context, and by identifying learning effects.

The remainder of the article is organized as follows. Section 2 presents the key design issues of the EU ETS. Section 3 examines the effects of banking restrictions between 2007 and 2008. Section 4 discusses the price fundamentals of $\mathrm{CO}_{2}$ allowances. Section 5 details market participants' risk behaviour. Section 6 concludes.

\section{Key Design Issues of the EU Emissions Trading Scheme}

This section reviews the scope, allocation methodologies, calendar, transactions levels, and penalties associated to non-compliance on the EU ETS.

\subsection{Scope}

The Directive 2003/87/CE defines the scope of the EU ETS ${ }^{6}$. This scheme concerns around 10,600 installations in Europe, mainly in the production sectors of combustion, iron and steel, pulp and paper, refineries, and cement. Installations in these sectors are eligible to

\footnotetext{
${ }^{6}$ See the European Commission Environment DG website at http://ec.europa.eu/environment/ets/
} 
emissions trading when their energy consumption is superior to the threshold of 20MWTh. This threshold has been decided by the European Commission so as to target the most energyintensive industries during the first Phases of the program. This choice has been justified initially by the will of the European Commission to minimize political resistance, and to enforce a quick implementation of the scheme in 2005. To increase the environmental performance of the scheme, the debate is now centred on the progressive extension of its scope. The EU ETS Review ${ }^{7}$ has revealed that other sectors will soon be included, such as aviation as of 2013.

\subsection{Allocation}

The $\mathrm{CO}_{2}$ emissions reduction target of each Member State has been converted into National Allocation Plans (NAPs). Each government is in charge of deciding the amount of quotas available for trading, after negotiating with industrials, and after the validation by the European Commission. The role of the Environment DG is central in this scheme in order to harmonize NAPs among Member States, and to recommend stricter NAPs validation criteria. The NAPs submissions may be rejected by the European Commission, and sent back to Member States for revision before the final decision. The sum of NAPs determines the number of quotas distributed to installations in the EU ETS. 2.2 billion of quotas per year have been distributed during 2005-2007. 2.08 billion of quotas per year will be distributed during 2008-2012, which corresponds to a more restrictive allocation, given some changes in the scope of the market with the inclusion of new Member States. Figures 1 and 2 represent, respectively, the repartition of quotas (in million tons of $\mathrm{CO}_{2}$ ) between Member States during the commitment periods 20052007 and 2008-2012 ${ }^{8}$. Germany, Poland, Italy, the UK and Spain total around two thirds of allowances distributed.

The allocation methodology consists in a free distribution of quotas in proportion of recent emissions, also known as grandfathering. With a value of around $€ 20$ per quota, the launch of the EU ETS corresponds to a net creation of wealth of around $€ 40$ billion. The environmental constraint during 2005-2007 has not been considered as sufficiently binding for most market observers, and the allocation methodology has been criticised for distributing rents to pre-existing market players, as some of them may make a net profit simply by selling their unused allowances.

During 2005-2007, allowances distributed have more than covered verified emissions, with a net cumulated surplus of 156 million tons. This surplus has however decreased, going from 83 million tons in 2005 to 37 million tons in 2006, and finally 36 million tons in 2007. Emissions have increased by $0.4 \%$ in 2007 compared to 2006, and reached 2,043 million tons with respect to 2,080 million allowances distributed.

\footnotetext{
${ }^{7}$ Available at http://ec.europa.eu/environment/climat/emission/reviewen.htm

${ }^{8}$ The data comes from the Mission Climat Caisse des Depots, available at: http://www.caissedesdepots.fr
} 


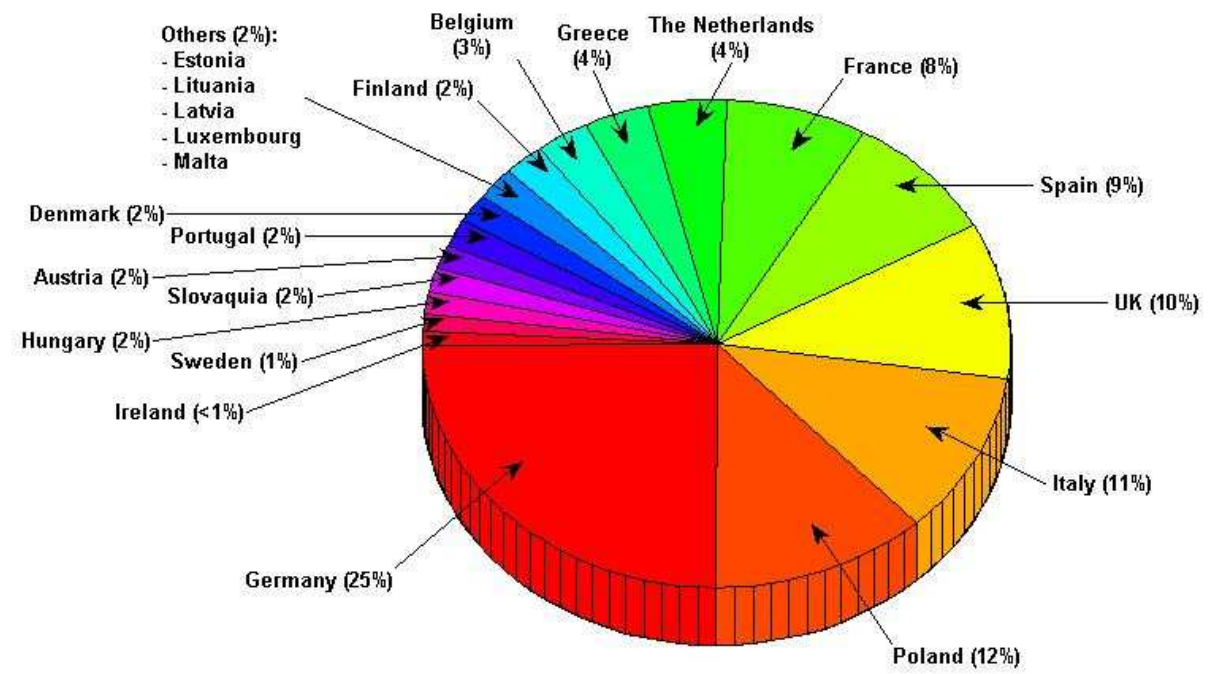

Figure 1: EU ETS National Allocation Plans - Phase 1 (2005-2007)

Source: CITL (2007) and CDC (2006)


Figure 2: EU ETS National Allocation Plans - Phase II (2008-2012)

Source: CITL (2008) and CDC (2008) 


\subsection{Calendar}

The EU ETS Phase I may be considered as a warm-up phase, during 2005-2007. Phase II corresponds to the commitment period of the Kyoto Protocol, i.e. 2008- 2012. Phase III is supposed to correspond to a post-Kyoto agreement, i.e. 2013- 2020. During each of these Phases, the delivery of allowances is made on a yearly basis, and follows a precise calendar:

- on February 28 of year $N$, European operators receive their allocation for the commitment year $N$;

- March 31 of year $N$ is the deadline for the submission of the verified emissions report during year $N-1$, from each installation to the European Commission;

- April 30 of year $N$ is the deadline for the restitution of quotas utilized by operators during year $N-1$;

- May 15 of year $N$ corresponds to the deadline of the official publication by the European Commission of verified emissions for all installations covered by the EU ETS during year $N-1$.

The annual frequency of verified emissions, imposed by the European Commission, corresponds thus to a central event, structuring the diffusion of reliable information at the aggregated level on the European carbon market.

\subsection{Transactions}

One allowance exchanged on the EU ETS corresponds to one ton of $\mathrm{CO} 2$ released in the atmosphere, and is called a European Union Allowance (EUA). Allowance trading is recorded electronically by national registries. The information contained in these registries is centralized by the European Commission in the European registry, called the Community Independent Transaction Log (CITL) ${ }^{9}$. The CITL contains exhaustive information on $\mathrm{CO}_{2}$ emissions for all installations covered by the EU ETS, and is used to account the compliance position of each firm. The information contained in the CITL is available at the installation level. As a first step, data compilation appears necessary to reconstruct the ownership structures between subsidiaries and parent companies, which yield to a more precise analysis for the evaluation of the scheme (McGuinness and Trotignon (2007)).

To comply with their emissions target, installations may exchange quotas either overthe-counter, or through brokers and market places. Bluenext, formerly Powernext Carbon, is the market place dedicated to $\mathrm{CO}_{2}$ allowance trading based in Paris. The European Climate Exchange is the market place based in London, which is leader for derivatives products. NordPool represents the market place common to Denmark, Finland, Sweden, Norway, and is based in Oslo. The price of products exchanged on these market places are strongly correlated,

\footnotetext{
${ }^{9}$ Available at: http://ec.europa.eu/environment/ets
} 
which is conform to other market places like stock markets. Moreover, the European carbon market is characterised by an increasing sophistication of financial instruments using a quota of $\mathrm{CO}_{2}$ as the underlying asset, and the development of option prices or swaps ${ }^{10}$.

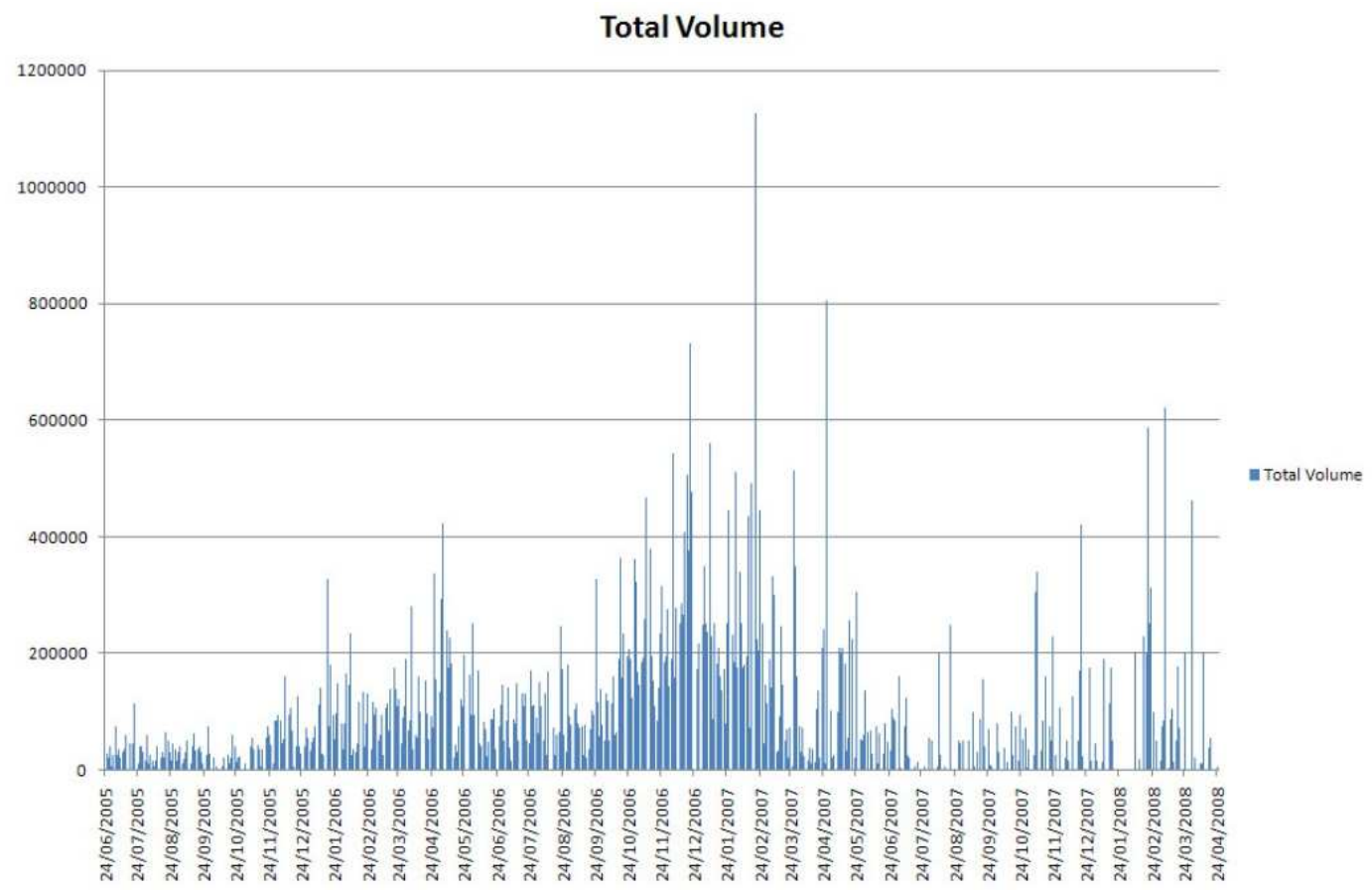

Figure 3: Volume exchanged for the spot price valid during 2005-2007 from June 24, 2005 to April 25, 2008 in tons of $\mathrm{CO}_{2}$

Source: BlueNext

Figure 3 indicates the total volume of allowances exchanged in the EU ETS during Phase I. This graph reveals that the number of transactions has been multiplied by a factor four between 2005 and 2006, going from 262 to 809 million tons. This increasing liquidity of the market has been confirmed in 2007, where the volume of transactions recorded equals 1.5 billion tons. This peak of transactions may be explained by the growth of the number of contracts valid during Phase II, with delivery dates going from December 2008 to December 2012 , which amount for $4 \%$ of total exchanges in 2005, and $85 \%$ in 2007 . These transactions reached $€ 5.97$ billion in 2005 , €15.2 billion in 2006 , and $€ 24.1$ billion in 2007 , thereby confirming the fact that the EU ETS represents the largest emissions trading scheme to date in terms of transactions.

${ }^{10}$ Note there exists also financial instrument with a CDM credit on the secondary market as the underlying asset, stemming from the Kyoto Protocol and fungible with quotas traded in the EU ETS with a maximum limit of around $13.4 \%$. 


\subsection{Penalties}

During 2005-2007, if an installation does not meet its emissions target during the compliance year under consideration, the penalty is equal to $€ 40 /$ ton in excess, plus the restitution of one allowance during the next compliance period. During 2008-2012, this amount corresponds to $€ 100 /$ ton, following the same principle.

Following this review of the institutional context on the European carbon market, we detail in the next section the allowance price development and associated banking strategies.

\section{Banking Provisions}

This section details the banking borrowing provisions adopted in the EU ETS. Intertemporal emissions trading allows firms to smooth their emissions overtime, and offers a greater flexibility in order to meet the emissions target. Therefore, banking and borrowing allow firms to achieve their depolluting objectives at least cost, if these provisions are adequately configured by the regulators and their effects has been sufficiently discussed, evaluated and understood. Let us first examine the allowance price development in the EU ETS during 20052007.

\subsection{Price Developments}

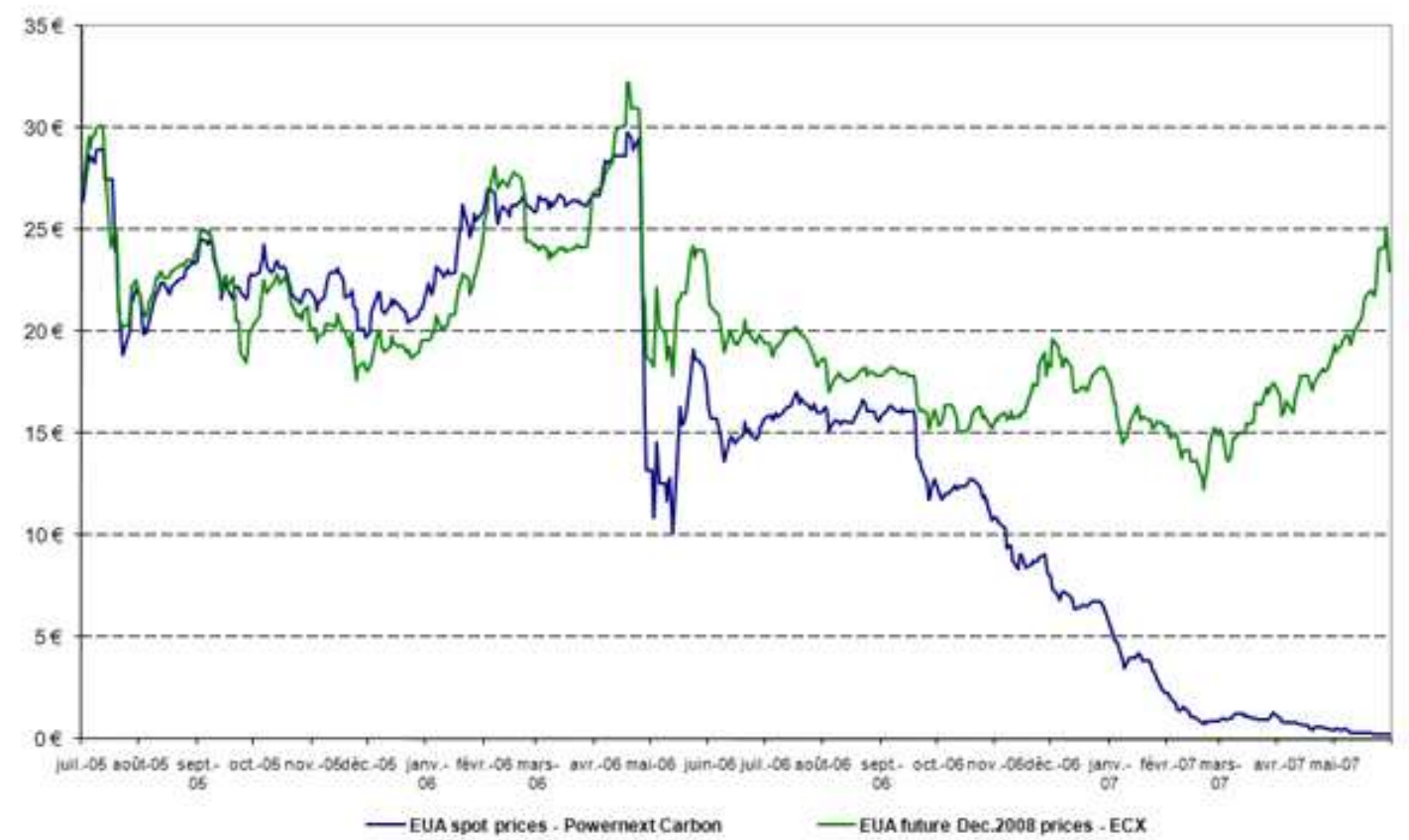

Figure 4: EUA Spot and Futures Prices from July 2005 to May 2007

Source: BlueNext and ECX 
In Figure 4, we may observe that from January to July $2005, \mathrm{CO}_{2}$ prices increased due to the perceived scarcity of allowances: demand comes mainly from power producers, while most other market participants did not take advantage of buying/selling carbon allowances. From August 2005 to March 2006, the volume of transactions increased, driving the equilibrium allowance price up to $€ 25 /$ ton of $\mathrm{CO}_{2}$. Demand continues to come primarily from power operators, and increased during the winter due to the rise of energy prices - especially gas prices. During April to May 2006, the allowance market encountered a sharp drop in prices of all maturities, due to the first compliance report by the European Commission revealing that the market was oversupplied by approximately $4 \%$. The allowance price is divided by a factor two within a window of four days only. Following this reversal of expectations from market operators, allowance prices stabilized around $€ 15 /$ ton of $\mathrm{CO}_{2}$ during June to September 2006. From October 2006 until the end of 2007, we finally observe a divorce between spot and futures prices of validity during Phases I (2005-2007) and II (2008-2012): while spot prices fell to $€ 0.5 /$ ton of $\mathrm{CO}_{2}$, futures prices remained in the range of 15 to $€ 20 /$ ton of $\mathrm{CO}_{2}$. The motives for such a disconnection between allowance prices of different maturities are explained in the next section. Since March 2007, allowance prices valid during 2008-2012 have stabilized over $€ 20 /$ ton of $\mathrm{CO}_{2}$, following the decision by the European Council to maintain the EU ETS at least until 2020, and the decision to enforce stricter validation criteria for NAPs II (Convery and Redmond (2007)).

\subsection{Banking Restrictions}

On the EU ETS, allowances are valid during a specific compliance year. However, an installation may have banked allowances during year $N$ to cover its emissions during year $N+1$, if years $N$ and $N+1$ correspond to the same Phase. The same mechanism applies for allowances borrowed from year $N+1$ in order to comply with the emissions target of the installation during year $N$. Thus, allowances banked or borrowed are fungible within the same Phase. However, allowances distributed during Phase I are not valid during Phase II. Allowances distributed during Phases II and III are fungible between the different Phases.

Phase I is characterized by a full intertemporal flexibility, like Phases II and III. Yet, given the simultaneity of the commitment periods between the Kyoto Protocol and Phase II, the intertemporal transfer of allowances has been strictly limited between Phases I and II, in effect banning the transfer of allowances between December 31, 2007 and January, 1, 2008.

Alberola and Chevallier (2009) develop a statistical analysis showing that the disconnection between Phase I prices, decreasing towards zero, and Phase II prices, stabilized around 20€/ton, may be explained by the restriction on the inter-period transfer of allowances enforced during Phase I. Indeed, the cost-of-carry relationship between EUA spot and futures 
prices for delivery during Phase II does not hold after the enforcement of the inter-period banking restrictions around October 2006.

The inefficiency of the EUA price signal to reflect correctly the social value of carbon until the end of Phase I may be explained by the restrictions enforced by Member-States concerning the transfer of quotas, banked or borrowed, from Phase I to Phase II. This sacrifice of the intertemporal flexibility mechanism may be interpreted by the will of the European Commission to limit the transfer of inefficiencies from the creation of the allowance market to Phase II, which simultaneously corresponds the Kyoto Protocol commitment period. Between Phases II and III of the EU ETS, the transfer of allowances has been authorized. Therefore, it appears possible to identify institutional learning effects between Phases I and II, as the early inefficiencies due to the youth of the European carbon market during 2005-2007 do not seem to have been transferred to the subsequent periods.

Moreover, preliminary analyses of the 2005-2007 data concerning the extent of the use of banking in the EU ETS may be found in Ellerman and Trotignon (2008) and Chevallier et al. (2008).

To further develop our analysis of price developments in the EU ETS, we conduct in the next section a review of the main price fundamentals of EUAs during 2005-2007.

\section{$4 \mathrm{CO}_{2}$ Price Fundamentals}

This section focuses on the price fundamentals of $\mathrm{CO}_{2}$ allowances. These fundamentals are mainly linked to regulatory decisions, energy prices and extreme temperatures events (Christiansen et al. (2005)).

\subsection{Institutional Decisions}

First, it is worth noting that political and institutional decisions on the overall cap stringency have an impact on the carbon price setting through initial allocation. Also, any decision or announcement from regulators may induce changes in market players' behaviour. From this perspective, official communications by the European Commission are essential to reach a better information flow on installations' net short/long positions ${ }^{11}$ (Ellerman and Buchner (2008)).

Whereas on energy markets the question of price formation is closely related to commodity storage, on the EU ETS the essential issue is the expected "emission shortfall" during each compliance year. The emission shortfall, defined as the difference between verified emissions during the compliance year and allocated allowances, depends on the actual amount

\footnotetext{
${ }^{11}$ Note an installation is defined as short (long) when it records a deficit (surplus) of allowances allocated with respect to actual emissions.
} 
of emissions abatements required (which are unknown but estimable based on reliable recent data) by the stringency of the cap (which is known). This information is publicly disclosed each year by the European Commission by mid-May as detailed in Section 2.3. It has a strong market effect on allowance price changes of all maturities, as it provides market participants with reliable information to update their expectations about future market developments.

Alberola et al. (2008) develop an original method to identify structural breaks in the $\mathrm{CO}_{2}$ price series. They provide statistical evidence that two institutional events on April 2006, following the disclosure of 2005 verified emissions, and on October 2006, following the European Commission announcement of stricter Phase II, occurred during 2005-2007. Those events have a sharp effect on market participants' expectations changes, and further allow isolating distinct energy and weather influences on carbon prices as discussed below.

\subsection{Energy Prices}

Second, energy prices are the most important price drivers on the short term of the EUA demand due to the ability of power generators to switch between their fuel inputs. This fuelswitching behaviour at the installations level applies especially in the power sector, which was endowed with more than $50 \%$ of EUAs during 2005-2007. The EU ETS price formation is indeed largely influenced by the electricity power market, since its participants are the main traders on the carbon market.

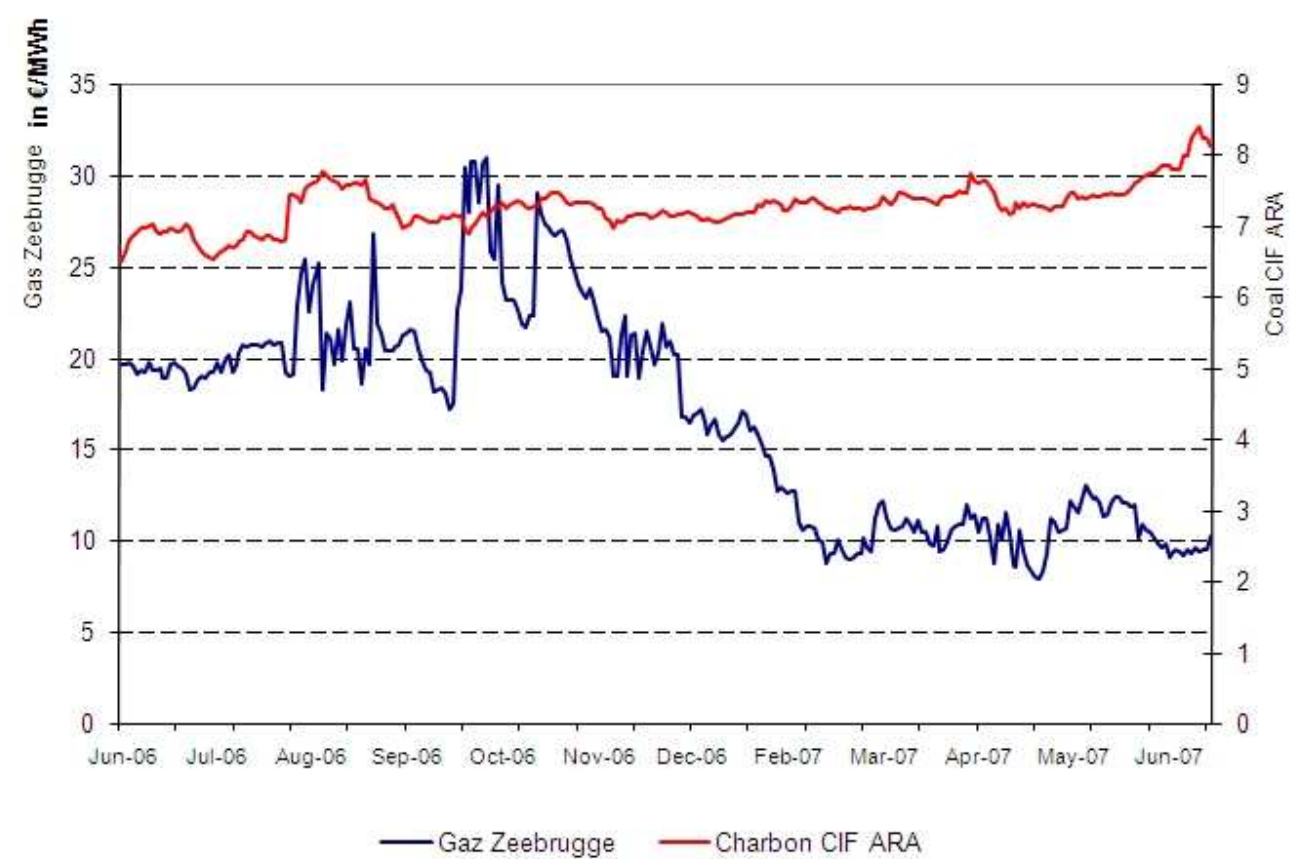

Figure 5: Gas Zeebrugge and Coal CIF ARA Prices from July 2006 to June 2007

Source: Thomson Financial Datastream 
Figure 5 shows the price development of natural gas and coal prices from July 2006 to June 2007. The natural gas price (in $€ / M W h$ ) is the daily futures Month Ahead natural gas price negotiated on Zeebrugge Hub. The price of coal (coal in $€ /$ ton) is the daily coal futures Month Ahead price CIF ARA ${ }^{12}$. During 2005-07, natural gas prices exhibit strong volatility compared to coal prices. During the months of November-December 2005, natural gas prices soared to $€ 50 / \mathrm{MWh}$ and steadily declined afterwards to €20/MWh during 2006, and to €10/MWh during the first quarter 2007. The competitiveness of natural gas compared to coal therefore improved during 2006 and the first quarter 2007 compared to the end of 2005.

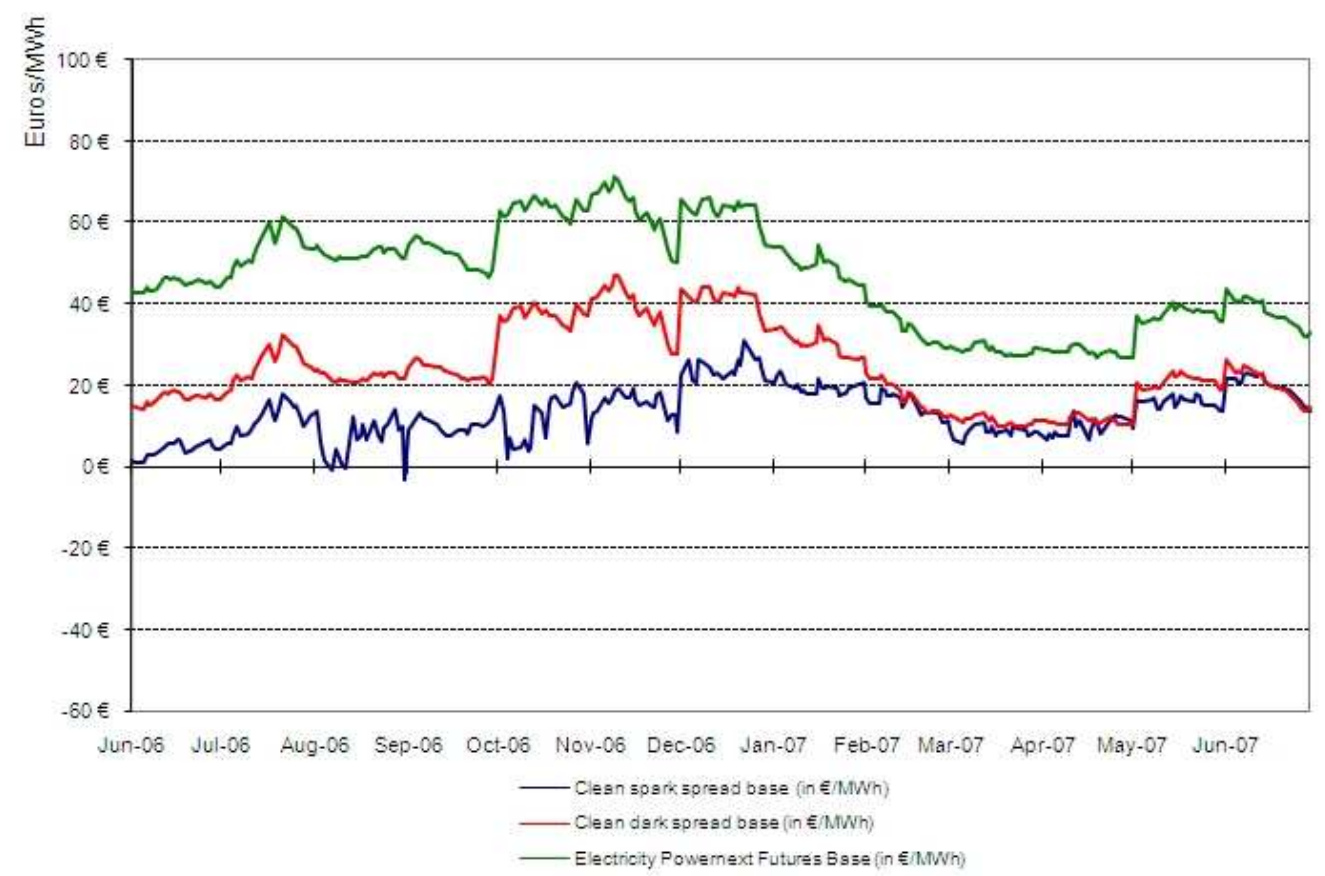

Figure 6: Clean Spark Spread, Clean Dark Spread and Electricity Powernext Prices from July 2006 to June 2007

Source: Thomson Financial Datastream

Figure 6 shows the price development of the electricity price, as well as the clean dark and clean spark spreads from July 2006 to June 2007. The price of electricity Powernext (in $€ / M W h)$ is the contract of futures Month Ahead Base. To take into account abatement options for energy industrials and relative fuel prices, it appears also important to introduce two specific spreads $^{13}$.

\footnotetext{
${ }^{12}$ CIF ARA denotes the price of coal inclusive of freight and insurance delivered to the large North West European ports, e.g. Amsterdam, Rotterdam or Antwerp.

${ }^{13}$ As calculated by the Mission Climat of the Caisse des Depots for Tendances Carbone. The methodology is available on the website:
} 
The Clean Dark Spread (in $€ / M W h$ ) represents the difference between the price of electricity at peak hours and the price of coal used to generate that electricity, corrected for the energy output of the coal plant and the costs of $\mathrm{CO}_{2}$ :

$$
\text { clean dark spread }=\text { elec }-\left(\operatorname{coal} * \frac{1}{\rho_{\text {coal }}}+p_{t} * E F_{\text {coal }}\right)
$$

with $\rho_{\text {coal }}$ the net thermal efficiency of a conventional coal-fired plant ${ }^{14}$, and $E F_{\text {coal }}$ the $\mathrm{CO}_{2}$ emissions factor of a conventional coal-fired power plant ${ }^{15}$.

The Clean Spark Spread (in $€ / M W h$ ) represents the difference between the price of electricity at peak hours and the price of natural gas used to generate that electricity, corrected for the energy output of the gas-fired plant and the costs of $\mathrm{CO}_{2}$ :

$$
\text { clean spark spread }=\text { elec }-\left(\text { ngas } * \frac{1}{\rho_{\text {ngas }}}+p_{t} * E F_{\text {ngas }}\right)
$$

with $\rho_{\text {ngas }}$ the net thermal efficiency of a conventional gas-fired plant ${ }^{16}$, and $E F_{\text {ngas }}$ the $\mathrm{CO}_{2}$ emissions factor of a conventional gas-fired power plant ${ }^{17}$.

During 2005-06, the use of coal appeared more profitable than gas. Since the beginning of 2007, the difference between the clean dark and clean spark spreads has been narrowing. This situation encourages consequently electric companies to decrease the use of coal to the profit of natural gas.

Figure 7 shows the price development of brent prices from July 2005 to November 2007. The oil price (in \$/baril) is the daily brent crude futures Month Ahead price negotiated on the Intercontinental Futures Exchange.

Alberola et al. (2008) show that energy prices forecast errors have basically driven the $\mathrm{CO}_{2}$ price over 2005-2007, but their influences changed over the period depending on regulatory changes. High levels of natural gas lead power operators to realise a switch in fuel utilization from gas to coal. The natural gas price got higher from October 2005 to April 2006 and thereby positively influenced the EUA price. As the most $\mathrm{CO}_{2}$-intensive variable, coal plays a negative role on carbon price changes: when confronted to a rise of the price of coal relative to other energy markets, firms have an incentive to adapt their energy mix towards less $\mathrm{CO}_{2^{-}}$ intensive energy sources. Brent prices have a positive effect on EUA price changes, which channels through the natural gas price (Kanen (2006)). These energy influences on carbon prices are also in line with Mansanet-Bataller et al. $(2007)^{18}$.

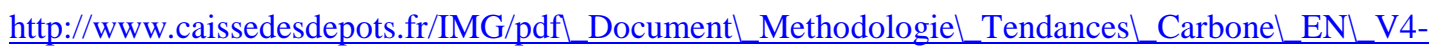
2.pdf

$\frac{14}{14}$ i.e. $40 \%$ according to the 2005 NEA/IEA report, The Projected Costs of Generating Electricity.

${ }^{15}$ i.e. $0.86 \mathrm{tCO}_{2} / \mathrm{MWh}$ according to the same source as above.

${ }^{16}$ i.e. $55 \%$ according to the same source as above.

${ }^{17}$ i.e. $0.36 \mathrm{tCO}_{2} / \mathrm{MWh}$ according to the same source as above.

${ }^{18}$ Note their study covers a shorter time-period, going from January 1, 2005 to November 30, 2005.
} 


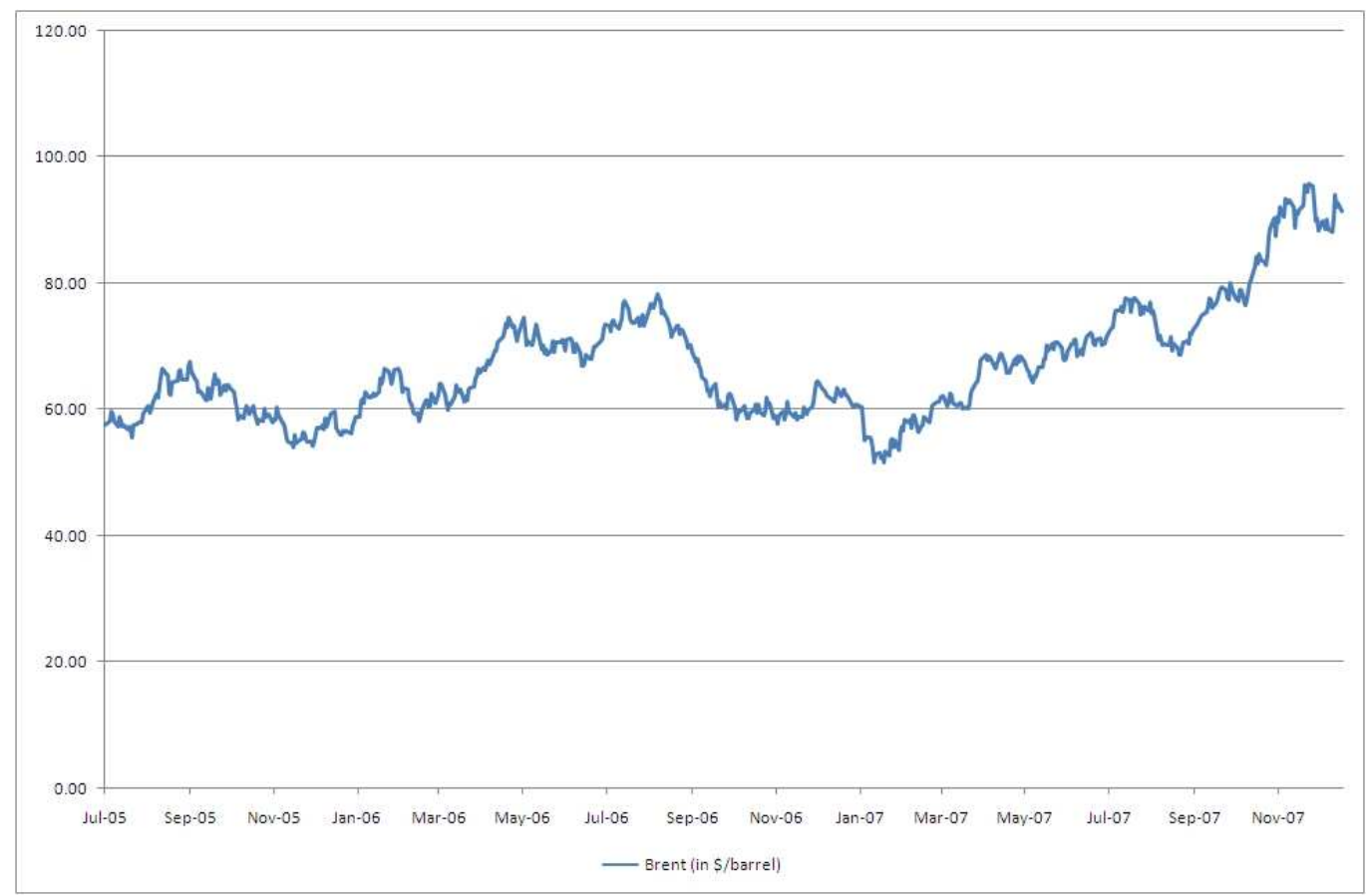

Figure 7: Brent ICE Prices from July 2005 to November 2007

Source: Thomson Financial Datastream

Let us discuss next weather influences on the EUA price formation.

\subsection{Extreme Weather Events}

Weather conditions have an impact on EUA price changes by influencing energy demand. Previous literature focuses on the most important dimension of weather: extremely hot and cold degree-days (Roll (1984)). Besides, we discuss the non-linearity of the relationship between temperatures and carbon price changes.

Weather influences may be captured by using the daily data of Powernext Weather indices (expressed in ${ }^{\circ} \mathrm{C}$ ) for four countries: Spain, France, Germany and the United Kingdom. These indices are computed as the temperature average at the representative regional weather station weighted by regional population:

$$
\Theta=\frac{\sum_{i=1}^{N} \text { pop }_{i} * \Theta_{i}}{\sum_{i=1}^{N} \text { pop }_{i}}
$$

with $N$ the number of regions in the country under consideration, $p p_{i}$ the population of region $i$, and $\Theta_{i}$ the average temperature of region $i$ during the month under consideration in ${ }^{\circ} \mathrm{C}$. 
The European temperature index published by Tendances Carbone $e^{19}$ may also be used. It is equal to the average of national temperatures indices provided by Powernext weighted by the share of each NAP in the previous four countries:

$$
T=\frac{\sum_{j=1}^{4} Q_{j} * \Theta_{j}}{\sum_{j=1}^{4} Q_{j}}
$$

with $Q_{j}$ the number of allowances allocated by the NAP in country $j$, and $\Theta_{j}$ the national temperature index of country $j$. The national share of allocation during Phase I in total allocation of EUAs are equal to $14.55 \%$ for France, $46.40 \%$ for Germany, $22.82 \%$ for the UK, and $16.23 \%$ for Spain, according to the European Commission.

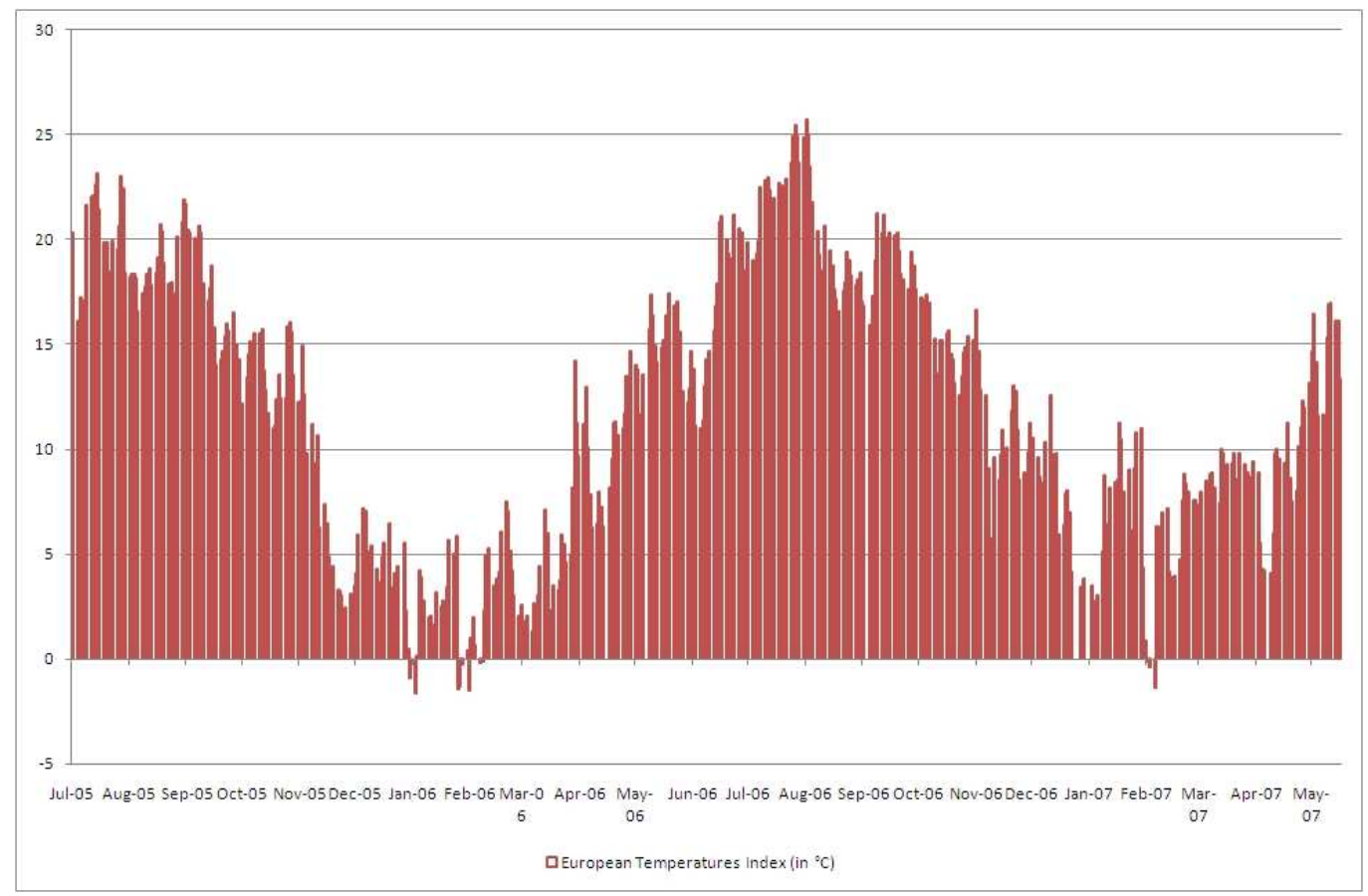

Figure 8: European Temperatures Index from July 2005 to May 2007

Source: Mission Climat - Caisse des Dépôts

Figure 8 represents the European Temperatures Index from July 2005 to April 2007. To take into account extreme weather conditions, Alberola et al. (2008) compute the deviation of the temperatures value from their seasonal average expressed in absolute value. They depart from previous literature by showing that unanticipated temperatures changes have a statistically

19 As calculated by the Mission Climat of the Caisse des Depots for Tendances Carbone. The methodology available on the website:

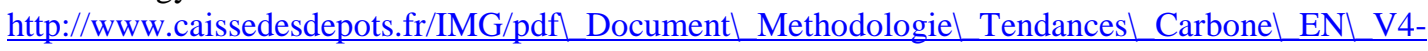
2.pdf 
significant effect on EUA prices only during some specific extreme weather events. During the winter 2006, colder temperatures than decennial averages have had a positive impact on EUA price changes. Similarly, during the summer 2006 and winter 2007, hotter temperatures have affected negatively carbon price changes. The economic rationale behind this analysis is that when extremely cold events are colder (hotter) than expected, power generators have to produce more (less) than they forecasted, which conducts to an increase (decrease) of allowances demand and finally to an increase (decrease) of $\mathrm{CO}_{2}$ price changes.

In this section, we have identified as $\mathrm{CO}_{2}$ price drivers energy prices, weather events, and institutional decisions during 2005-2007. Linked to the influence of political, energy, climatic and economic uncertainties on $\mathrm{CO}_{2}$ price changes, we discuss in the next section adequate risk-hedging strategies on the EU ETS.

\section{Risk-Hedging Strategies}

This section deals with the risk-hedging strategies used by firms. Investors naturally attempt at hedging against a variation of the risk attached to allowance trading, especially given the institutional amendments to the functioning of the scheme. We discuss first the introduction of option prices in the EU ETS, and second the consequences on market participants' hedging strategies.

\subsection{Carbon-based derivatives products}

Investors need to manage the risk of holding $\mathrm{CO}_{2}$ allowances on the European carbon market among a portfolio of diversified investments. As on financial markets, the uses of derivatives products allow to reduce the risk of a position on emissions markets. Indeed, the European Climate Exchange launched on October 2006 derivatives products trading carbon allowances as the underlying asset.

Figure 9 displays option prices available along with several strikes from October 2006 to October 2007 on ECX. As detailed in Section 2.4, ECX is the most liquid trading platform with approximately $86.5 \%$ of the total exchange-based trades of allowances. The underlying assets of the contracts are first and second period spot prices. The maturity of the contracts typically range from December 2008 to 2013, Phase II contracts (2008-2012) being more actively traded than post-Kyoto contracts. Option prices on the carbon market lead to pricing errors that are usual for commodity or equity markets. On such a commodity market, the easiest way to hedge against the risk of allowance price changes is by selling calls: call prices are more actively traded than puts. 


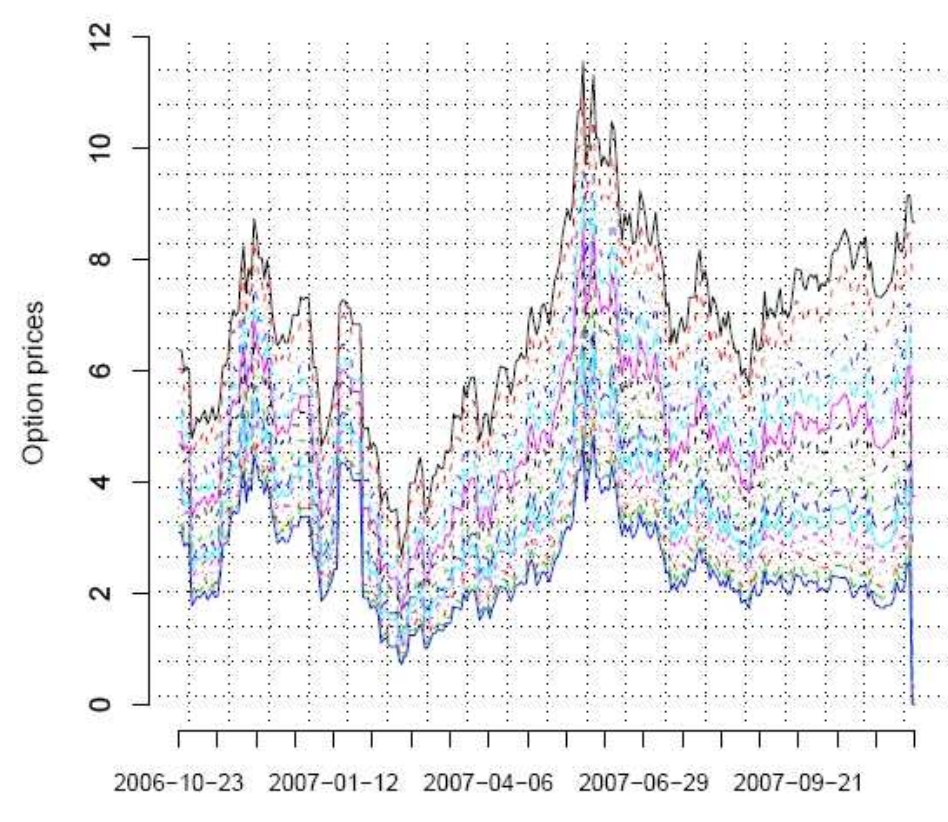

Time

Figure 9: Option prices available along with several strikes from October 2006 to October 2007.

Source: ECX

Since option prices transfer the risk of financial exposure between market agents, we further detail in the next section agents' behaviour with respect to risk on this newly created commodity derivatives market.

\subsection{Investors' risk aversion}

Chevallier et al. (2009) estimate changes in investors' risk aversion on the European carbon market around the 2006 compliance event ${ }^{20}$. They recover investors' risk aversion by using the existing relationship with the risk-neutral and historic probabilities. This methodology has proved to be robust for stock markets. First, the risk-neutral distribution is recovered from ECX option prices. Second, the historical distribution is approximated by the historical return distribution of futures allowance prices. Third, the risk aversion is obtained as a by-product (Leland (1980)).

\footnotetext{
${ }^{20}$ Given the central role played by the 2005 compliance event highlighted in Section 3.1, we focus on the 2006 compliance event, which is the only event empirically observable following the introduction of options trading on ECX.
} 


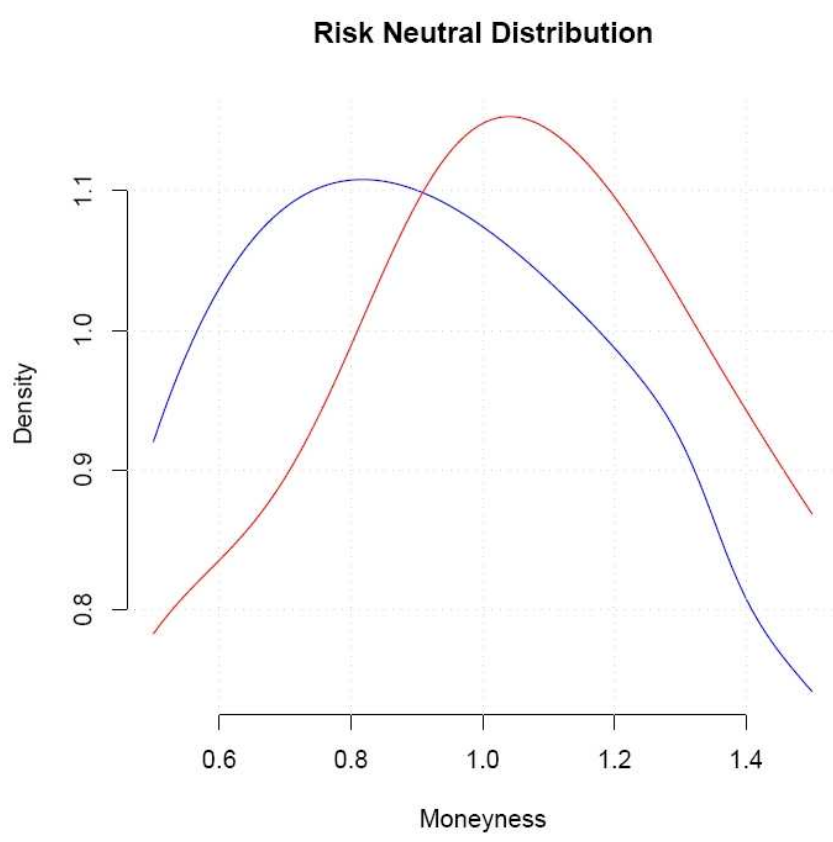

Figure 10: Changes in the Risk Neutral Distribution for the December 2008 Futures Contract.

Source: Chevallier et al. (2009)

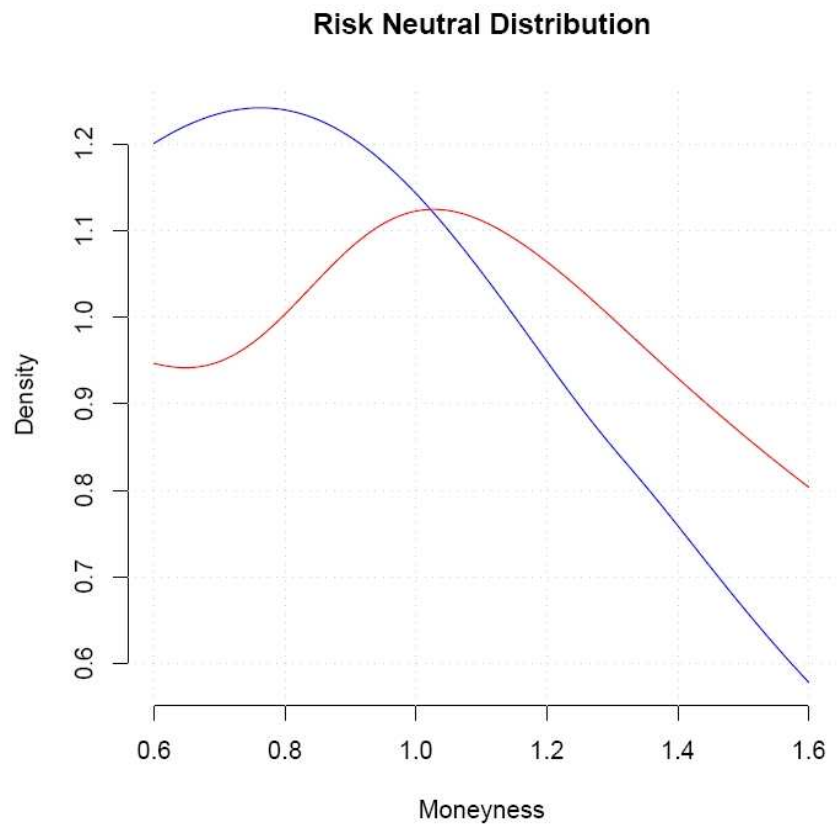

Figure 11: Changes in the Risk Neutral Distribution for the December 2009 Futures Contract.

Source: Chevallier et al. (2009) 

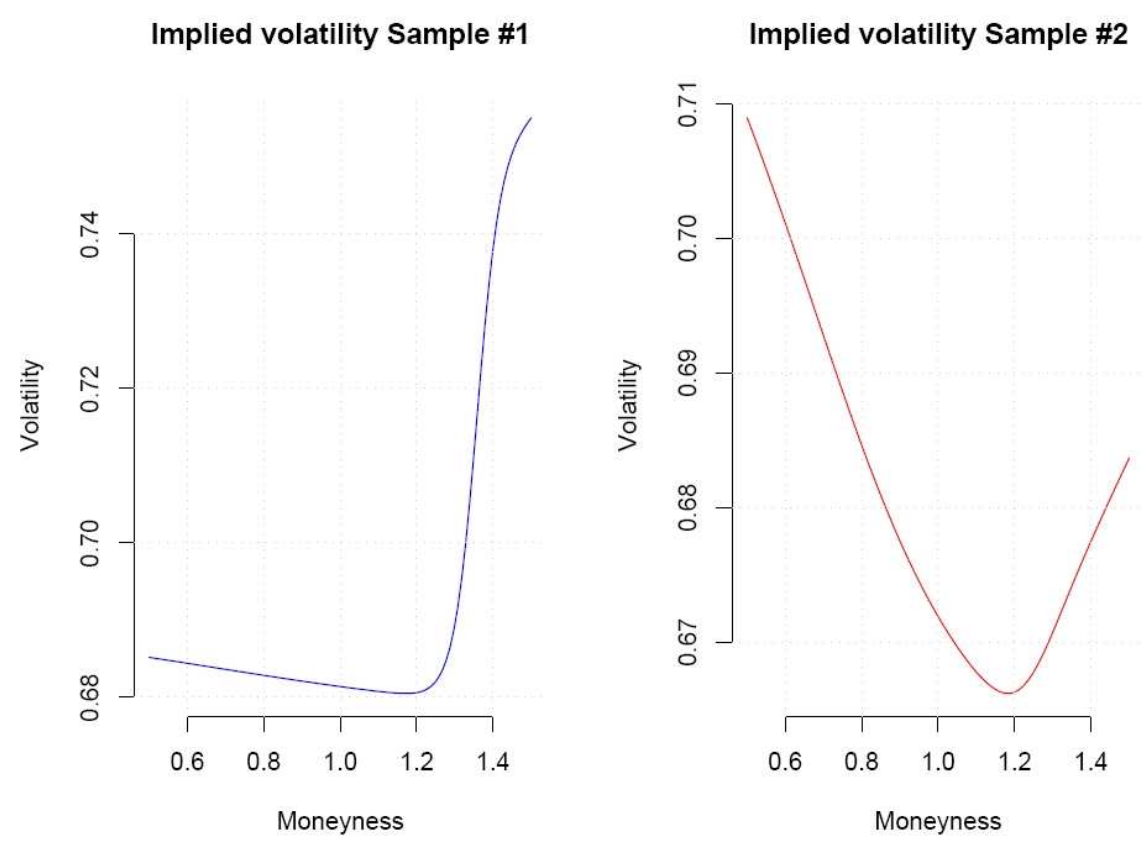

Figure 12: Changes in the Implied Volatility for the December 2008 Futures Contract. Source: Chevallier et al. (2009)

Note: the blue line denotes the risk neutral density before the 2006 compliance event, while the red line denotes the risk neutral density after this institutional event.
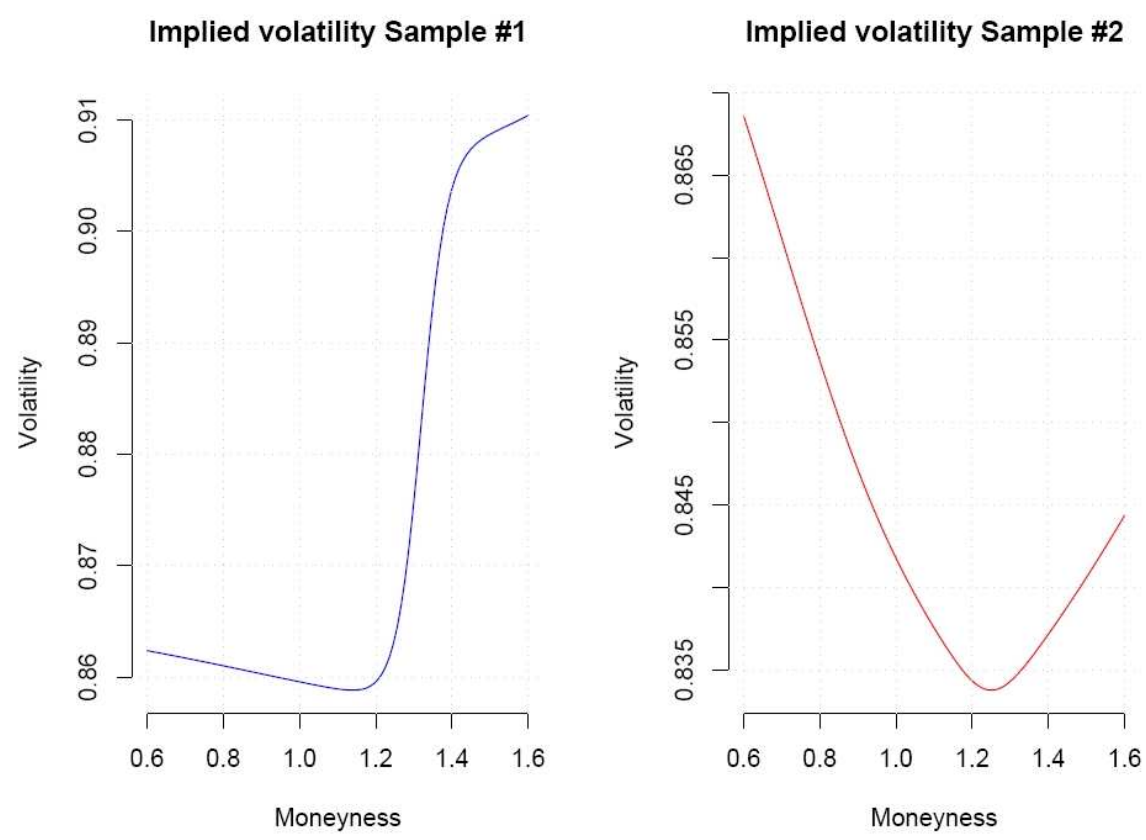

Figure 13: Changes in the Implied Volatility for the December 2009 Futures Contract.

Source: Chevallier et al. (2009)

Note: the blue line denotes the risk neutral density before the 2006 compliance event, while the red line denotes the risk neutral density after this institutional event. 
Figures 10 and 11 represent changes in the risk neutral distribution for the futures contracts of maturity, respectively, December 2008 and December 2009. For both figures, the blue line denotes the risk neutral density before the 2006 compliance event, while the red line denotes the risk neutral density after this institutional event. The blue line has a steeper slope than the red line, which induces more volatility. These results are consistent with the role of information in lowering volatility on financial markets.

Figures 12 and 13 represent changes in the implied volatility for the futures contracts of maturity, respectively, December 2008 and December 2009. These two figures illustrate the dramatic changes in investor's risk aversion around the 2006 compliance event, as the implied volatilities exhibit dramatically different slopes depending on the sample considered. By extracting the information contained in option and futures prices, these results uncover a dramatic shift in investors' anticipation around the 2006 compliance event.

Overall, this study provides an efficient tool to quantify the effects of risk aversion on the European carbon market which, during the period under consideration, has been higher than on the stock market. This situation underlines the necessity for investors to manage adequately the risk attached to holding $\mathrm{CO}_{2}$ allowances. With the start of Phase II on a sound institutional framework, risk aversion on the European carbon market is likely to tend progressively towards the values found on stock markets.

\section{Concluding Remarks}

This article reviews the market rules of the European carbon market during 2005-2007. The synthesis of theoretical and empirical approaches developed here has been fruitful for the analysis of banking, pricing and risk-hedging strategies. These results teach us that institutional learning has indeed occurred within Phase I, both from the viewpoint of market agents and the regulator.

The banking restrictions enforced between December 2007 and January 2008 in the EU ETS led to the disconnection between spot prices valid during Phase I, which plummeted to zero, and futures prices valid during Phase II, which remained stable around $€ 20$ throughout the period. This particular episode of the EU ETS highlights the necessity to understand the underlying mechanisms of $\mathrm{CO}_{2}$ price changes.

Like other commodity markets, the amount of allowances available for trading and thus the EUA price are driven by the balance between supply and demand (energy prices, weather variables, etc.), and other factors related to market structure and institutional policies. Decision changes within the regulatory environment have a sharp market effect on allowance prices of all maturities. These structural breaks may be statistically identified within the time series of carbon prices, and are linked to yearly compliance events and to official communications by the European Commission. Besides, it is possible to isolate the influence of carbon price 
fundamentals linked to energy prices and extreme weather events, which varies before and after institutional events.

Carbon allowances therefore form another asset in commodities against which industrials and brokers need to hedge. Studies based on methods used on stock markets prove to be robust in quantifying changes in investors' anticipations.

Overall, this article highlights the inefficiencies following the creation of the European carbon market that prevented the emergence of a price signal leading to effective emissions reductions by industrials. The early design inefficiencies of the European carbon market, linked to initial allocation or the inter-period transfer of allowances, seem to have been corrected for the period 2008-2012, thereby limiting the transfer of inefficiencies towards Phase II. 


\section{References}

Alberola, E., and Chevallier, J. 2009. 'European Carbon Prices and Banking Restrictions: Evidence from Phase I (2005-2007)'. The Energy Journal 30(3), 107-136.

Alberola, E., Chevallier, J., and Cheze, B., 2008. 'Price Drivers and Structural Breaks in European Carbon Prices 2005-2007'. Energy Policy 36(2), 787-797.

Chevallier, J., Etner, J., and Jouvet, P.A. 2008. 'Bankable Pollution Permits under Uncertainty and Optimal Risk-Management Rules: Theory and Empirical Evidence'. Working Paper EconomiX-CNRS 2008-25.

Chevallier, J., Ielpo, F., and Mercier, L. 2009. 'Risk Aversion and Institutional Information Disclosure on the European Carbon Market: A Case-Study of the 2006 Compliance Event'. Energy Policy 37(1), 15-28.

Christiansen, A., Arvanitakis, A., Tangen, K., Hasselknippe, H., 2005. 'Price determinants in the EU emissions trading scheme'. Climate Policy 5, 15-30.

CITL. 2007. 'Community Independent Transaction Log'. European Commission. available at http://ec.europa.eu/environment/ets

CITL. 2008. 'Community Independent Transaction Log'. European Commission. available at http://ec.europa.eu/environment/ets

CDC. 2006. 'Research Bulletin Number 8'. Mission Climat of Caisse des Dépôts, Paris. available at http://www.caissedesdepots.fr

CDC. 2008. 'Research Bulletin Number 20'. Mission Climat of Caisse des Dépôts, Paris. available at http://www.caissedesdepots.fr

Convery, F.J. 2009. 'Reflections - The Emerging Literature on Emissions Trading in Europe'. Review of Environmental Economics and Policy 3(1), 121-137.

Convery, F.J., Ellerman, D., de Perthuis, C. 2008. 'The European Carbon Market in Action: Lessons from the First Trading Period'. Interim Report. MIT-CEEPR, Mission Climat Caisse des Dépôts and University College Dublin.

Convery, F.J. and Redmond L. 2007. 'Market and Price Developments in the European Union Emissions Trading Scheme'. Review of Environmental Economics and Policy 1(1), 88-111.

Ellerman, D. and Buchner, B. 2008. 'Over-Allocation or Abatement? A Preliminary Analysis of the EU ETS Based on 2005 Emissions Data'. Environmental and Resource Economics 41, 267287.

Ellerman, D. and Trotignon, R. 2008. 'Compliance Behavior in the EU ETS: Cross Border Trading, Banking and Borrowing'. MIT-CEEPR Working Paper 2008-12.

Kanen, J.L.M. 2006. Carbon Trading and Pricing. Environmental Finance Publications.

Leland, H.E. 1980. 'Who Should Buy Portfolio Insurance?' The Journal of Finance 35(2), 581594. 
Mansanet-Bataller, M., Pardo, A., Valor, E., 2007. ' $\mathrm{CO}_{2}$ Prices, Energy and Weather'. The Energy Journal 28 (3), 67-86.

McGuinness, M., and Trotignon, R. 2007. 'Technical Memorandum on Analysis of the EU ETS Using the Community Independent Transaction Log'. MIT-CEEPR Working Paper 2007-12.

Roll, R. 1984. 'Orange Juice and Weather'. The American Economic Review 74(5), 861-880.

UNFCCC. 2000. 'Procedures and Mechanisms Relating to Compliance under the Kyoto Protocol: Note by the co-Chairmen of the Joint Working Group on Compliance', United Nations Framework Convention on Climate Change, Bonn. Report. 